\title{
RECENT SOLAR ACTIVITY
}

\author{
By Dr. M. A. ELLISON \\ Royal Observatory, Edinburgh
}

\begin{abstract}
HE present maximum phase of the sunspot cycle is outstanding in many respects. The Zurich relative sunspot numbers (provisional) for the first ten months of 1957 were: $152,117,157$, $175,165,206,194,163,244,263$. These high values for September (244) and October (263) are quite exceptional. If we look back to the beginning of the series in 1749 , the only other monthly means which have exceeded the 200 level were those of May 1778 (239), December 1836 (206), May 1947 (201) and November 1956 (203). We may thus regard the timing of the opening months of the International Geophysical Year as particularly fortunate : to have caught so great a peak of solar activity within its net was a considerable achievement of planning.

The high sunspot numbers of 1957 have been contributed mainly by the occurrence of large numbers of small and medium-sized spot groups. On many days in September and October there have been upwards of twenty such groups present on the disk at one time. On the other hand, the giant $F$-type sunspots which were such a characteristic feature of the last cycle, in the years 1946-51, have been noticeably few. It is spots of this type, possessing complex magnetic fields ( $\beta \gamma$ and $\gamma$ ), which give rise to the most intense $(3+)$ solar flares, and these have likewise been less frequent than the high sunspot numbers would lead one to expect.

Another unusual feature has been the continued appearances of occasional spots in high latitudes, such as are characteristic of the early years of the cycle. One of these groups, in latitude $46^{\circ} \mathrm{S}$., crossed the central meridian on September 15 and lasted for at least seven days.

September also provided something like a record in magnetic activity: there were, in all, six great storms with sudden commencements, beginning on September 2, 4, 13, 21, 22 and 29. Two regions showing high flare activity (one in $20^{\circ} \mathrm{N}$. and the other in
\end{abstract}

\section{ECOLOGY OF GRASSLANDS}

$\mathrm{O}^{\mathrm{s}}$ September 11 in Dublin, Section K (Botany) and Section $M$ (Agriculture) of the British Association held a joint session under the chairmanship of Prof. J. Doyle on "The Ecology of Grasslands". Mr. C. E. Hubbard opened with a paper on "Genetical and Ecological Variation of the Components of Grasslands in the British Isles". Speaking as a taxonomist, Mr. Hubbard pointed out that while the botanist was primarily interested in characters distinguishing taxa and especially those indicative of relationship, the agriculturist was essentially concerned with characteristics likely to be of value for grassland improvement and only those varieties likely to be of economic importance were of prime interest to him. Variability in grass populations had long been recognized. A. F. Gray in 1821 recorded seventy-five varietios of wild British grasses, while nowadays the number of intraspecific variants recorded exceeded four hundred. Mr. Hubbard then presented a classification of grass variants and distinguished between those of some taxonomic sig- $30^{\circ} \mathrm{S}$. latitude) crossed the Sun's central meridian on August 31, and to these must be attributed the great geomagnetic disturbances during September 2-5. One of the few $F$-type sunspots developed rapidly from September 14 onwards, crossing the central meridian on September 19. This region generated a high level of activity-at least a dozen flares were observed here in the class 2 and 3 categories - and was undoubtedly responsible for the magnetic storms on September 21 and 22. Another active group, with central meridian passage on September 27, was the probable cause of the storm on September 29.

Prof. J. Bartels reports that, for September, the monthly average of the daily planetary magnetic amplitudes, $A p$, in the usual unit of 2 gamma, was 49. The next highest monthly averages in the available series (1932-33, and 1937 to date) were 40 (September 1951) and 37 (March 1940). September had three days with $C p=2.0$ and five days with $C p=1 \cdot 9$.

Some thirty-six sudden ionospheric disturbances (cases of $D$-layer absorption due to solar flares) were recorded in Britain during daylight hours in September. Many of these produced severe fade-outs on $18 \mathrm{Mc} / \mathrm{s}$. and lower frequencies, such as are usually associated with flares of classes 2 and $3 . \quad F$-layer radio reception with North America was particularly disturbed, especially at the times of the large magnetic storms referred to above.

Although the sunspot number for October exceeded the high value in September, active solar regions were loss pronounced and their terrestrial effects were on a considerably smaller scale. A 3 + flare, observed at the McMath-Hulbert Observatory, reached its peak intensity at about $17 \mathrm{~h} .00 \mathrm{~m}$. on October 20. This outburst would appear, on a provisional view, to have been the most likely souree of the magnetic storm particles which began to affect the ionosphere on the afternoon of October 21.

nificance and others of a more trivial nature. Diseased or abnormal states were seldom of any ecological or genetical significance. Colour variants, however, might be due to ecological or genetical factors: the colour-spikeleted forms of Deschampsia caespitosa, for example, were definitely genetical in character. Albinism, on the other hand, when almost complete, usually led to early death. Partial albinism producing variation, however, was often an unstable condition, and reversion was not unusual. Anatomical variation included the pruinose and glaucous condition due to a waxy surface layer or a thick cuticle, and the rigidity or otherwise of a grass depending on the amount and arrangement of sclerenchymatous tissue. This last condition was probably of ecological significance only. The degree of hairiness of a grass was a very variable factor. Some genetically fixed hairy variants existed, but the range of hairiness of the spikelets found, for example, in a population of the microspecies of the Bromus mollis complex was doubtless due to hybridization. A number of trivial 